\title{
LIFE IS WHAT WE MAKE OF IT \\ UMA ABORDAGEM SOCIOLÓGICA AOS SIGNIFICADOS DE FELICIDADE
}

\author{
LIFE IS WHAT WE MAKE OF IT \\ A SOCIOLOGICAL STUDY ON HAPPINESS MEANINGS
}

\author{
Ana Roque Dantas \\ Centro Interdisciplinar de Ciências Sociais (CICS.NOVA), Faculdade de Ciências Sociais e Humanas, \\ Universidade NOVA de Lisboa, Av. de Berna, 26 C, 1069-061 Lisboa, Portugal. Email: ana.roque@fcsh.unl.pt
}

\begin{abstract}
Resumo: A ideia de felicidade, omnipresente nas sociedades ocidentais actuais, assume-se como princípio orientador e como objectivo de vida. Contudo, o facto de a felicidade ocupar pensamentos individuais não a torna uma experiência unicamente privada e singular. A sua idealização é socialmente moldada, interpretada e partilhada e traduz formas culturais de pensar, ser e agir.

Partindo dos resultados de um inquérito sociológico por questionário a uma amostra da população da Área Metropolitana de Lisboa, aplicado na cidade de Lisboa, exploram-se os significados de felicidade na sua relação com as circunstâncias de vida em que são produzidos.

Os resultados revelam que os significados sociais de felicidade e as orientações da acção são socialmente diferenciados e incorporam desigualdades sociais mais vastas. Assim, interpretar e procurar felicidade não são opções meramente individuais, destacadas da organização social. Ainda que associadas pelos inquiridos às capacidades individuais e qualidade das suas decisões, estão profundamente marcadas pelas circunstâncias, pelos percursos e pelo meio social de inserção.
\end{abstract}

Palavras-chave: felicidade, sociologia da felicidade, sociologia das emoções, significados de felicidade.

\begin{abstract}
The idea of happiness, omnipresent in today's western societies, is a life goal. However, the fact that happiness occupies individual thoughts does not make it a private and singular experience. Happiness idealization is socially shaped, interpreted and shared, translating cultural ways of thinking, being and acting.

Based on the results from a sociological survey using a questionnaire applied to a sample of residents of the Lisbon Metropolitan Area, and carried out in the city of Lisbon, we explore the meanings of happiness in relation to the life circumstances in which they are produced.

Results show that the meaning of happiness is socially differentiated. Moreover, it incorporates broader social inequalities. Consequently, interpreting and seeking happiness are not merely individual choices, detached from the social setting. These are associated by the respondents with individual capacities and decisions, however, they are deeply marked by individuals circunstances, paths and social backgrounds.
\end{abstract}

Keywords: happiness, sociology of happiness, sociology of emotions, happiness meanings.

\section{Introdução}

A ideia de felicidade, omnipresente nas sociedades ocidentais actuais, chega-nos através da cultura, dos media, da publicidade e assume-se como princípio orientador e 
como objectivo de vida. A concepção de felicidade partilhada começa a formar-se na Grécia antiga, é cultivada e moldada pela tradição judaico-cristã e floresce com o Iluminismo, tornando-se a partir daí um imperativo da existência humana. Assenta na crença de que cabe aos actores sociais melhorar as suas condições e a vida da sociedade em geral. Esta ideia de livre exercício das capacidades humanas, que está na base da construção das sociedades modernas, contaminou os ideais de felicidade, nomeadamente a crença de que esta é um direito (tal como fica expresso na declaração de independência dos Estados Unidos da América) e que deve ser conquistada por iniciativa pessoal e não por recompensa divina (Joshanloo, Lepshokova, Panyusheva, Natalia, Poon, Yeung, Sundaram, Achoui, Asano, Igarashi, Tsukamoto, Rizwan, Khilji, Ferreira, Pang, Ho, Han, Bae \& Jiang, 2013; McMahon, 2009; 2010).

Simultaneamente, sabemos que os pensamentos sobre felicidade são frequentes e recorrentes (Joshanloo \& Weijers, 2014), concorrendo para a formação de sentido sobre a vida, para a criação do seu significado e para a definição das orientações face ao futuro. Pensar sobre felicidade só por si capacita as pessoas para falarem sobre as formas como a experienciam, a entendem, a procuram e a desejam. No entanto, o facto da felicidade ocupar pensamentos individuais não a torna uma experiência unicamente privada e singular. A sua idealização é socialmente molda$\mathrm{da}$, interpretada e partilhada, sendo que traduz formas culturais de pensar, ser e agir. Neste sentido, a ideia de felicidade incorpora aspectos sociais e assume diferentes significados. Assim, e tal como a literatura tem vindo a sugerir, a ideia de felicidade é socialmente diferenciada (Baudelot \& Gollac, 2003; McMahon, 2009; Roque Dantas, 2012), constituindo-se como o resultado de influências interligadas de factores estruturais, de condições de vida e de especificidades individuais (Frey \& Stutzer, 2001; Graham, 2011a; Veenhoven \& Jonkers, 1984). Tendo por base estudos anteriores que identificam diferentes concepções de felicidade - umas mais ligadas à posse, outras à execução - e que sugerem que estas concepções poderão ser socialmente determinadas (Baudelot \& Gollac, 2003; Roque Dantas, 2012), importa perceber se existem diferenças sociais associadas às formas de procurar, entender e expressar felicidade.

É este o objectivo deste artigo: explorar a diferenciação social dos significados atribuídos a felicidade. Para tal, seguidamente começaremos por rever os principais contributos teóricos existentes sobre esta temática. Em seguida, será apresentada a metodologia, para depois expor os principais resultados. A finalizar, os resultados serão discutidos nas considerações finais. 


\section{Enquadramento teórico}

Nos últimos anos, assistimos a um aumento sem precedentes dos estudos científicos sobre felicidade ${ }^{1}$. Na sua maioria, estes estudos seguem metodologias extensivas, baseadas em medidas de avaliação subjectiva (esta avaliação é feita por meio do julgamento individual que cada um faz da sua vida, da forma como se sente e como a avalia face às condições existentes, face ao outro e face ao seu próprio modelo de referência). Estas abordagens permitem a análise da evolução dos níveis médios de felicidade (análises longitudinais), a comparação entre países, bem como explorar as relações existentes com outras variáveis de interesse. Possibilitam, por isso, conhecer variações, causas e consequências da felicidade. A coerência dos resultados de vários estudos, incidindo sobre diversas realidades, permitiu identificar os principais aspectos que influenciam a percepção de felicidade (Graham, 2011a). Desta forma, é possível saber que a felicidade resulta da influência conjunta de diferentes dimensões interdependentes (sociais, económicas e individuais). Mais especificamente, sabemos que a felicidade se relaciona com a situação política de um país, nomeadamente com a democracia (estabilidade e responsabilidade ou accountability dos governos), bem como com a liberdade política e a participação nas estruturas democráticas (Frey \& Stutzer, 2000; 2001; Graham, 2011b; Helliwell, 2003; Inglehart, Foa, Peterson \& Welzel, 2008). A nível económico, refira-se a importância que as desigualdades sociais e a percepção de segurança (nomeadamente quando abalada por crises económicas), têm (negativamente) sobre a percepção de felicidade (Alberto Alesina, Di Tellab \& MacCulloch, 2004; Frey, 2009; Frey \& Stutzer, 2001; Graham, 2011b; Pickett \& Wilkinson, 2011; Veenhoven \& Jonkers, 1984; Yang, 2008). Da mesma forma, estão amplamente identificados os efeitos do emprego sobre as percepções de felicidade, como sejam as características do trabalho desenvolvido (Baudelot \& Gollac, 2003), o desemprego e os rendimentos auferidos (Easterlin, 2001; Graham, 2011a; Layard, 2005). Sabemos igualmente que as relações interpessoais - quantidade e qualidade dos relacionamentos tanto em contextos sociais como pessoais - assumem especial relevo para uma avaliação positiva da forma de sentir (Argyle, 2013a). Entre as características individuais, reconhece-se a importância da idade (Blanchflower \& Oswald, 2008; Roque Dantas, 2015; Veenhoven \& Jonkers, 1984), dos valores socialmente partilhados (Inglehart, Foa, Peterson \& Welzel, 2008; Welzel, Inglehart \& Kligemann, 2003) e das motivações e estilos de vida (Argyle, 2013b; Csikszentmihalyi, 1997; Hills \& Argyle, 1998; Veenhoven \& Jonkers, 1984).

Estes estudos, assentes em metodologias extensivas que avaliam a percepção subjectiva dos indivíduos acerca da sua felicidade, dão resposta a solicitações 
sociais e políticas no sentido de produzir indicadores estatísticos sobre as percepções das populações acerca do seu bem-estar e que complementam os indicadores económicos e sociais. No entanto, por se basearem em medidas subjectivas (cada pessoa entra em consideração com os aspectos que considera mais relevantes) não sabemos se é o resultado de uma reflexão consciente nem que dimensões reflecte. Estas abordagens não permitem, por isso, aceder a significados, práticas e representações sociais de felicidade, ou analisar as circunstâncias ou acontecimentos da vida em que ocorre a avaliação.

Complementarmente, alguns trabalhos centram-se na análise de narrativas procurando a compreensão aprofundada de felicidade. Os resultados mostram que, mais do que uma experiência pessoal e privada, a felicidade é moldada, interpretada e articulada socialmente. Mais ainda, as formas como as pessoas falam sobre felicidade e se auto-posicionam nos discursos é uma forma de participação e criação de um sentido comum do que é a felicidade (Hyman, 2014; Oishi, Graham, Kesebir \& Galinha, 2013). Revelam igualmente a importância que a felicidade assume na tomada de decisão e na orientação da acção (Roque Dantas, 2012). Contudo, estes estudos trabalham com amostras de dimensão reduzida, não permitindo uma compreensão mais vasta da influência do contexto sócio-cultural em que se produzem e transformam as expressões e significações de felicidade.

Face a estas limitações, pretendemos agora aprofundar o conhecimento sobre os significados de felicidade, nomeadamente como diferentes colectivos sociais produzem e reproduzem a sua interpretação de felicidade. Mais concretamente, propomos uma abordagem focada nas percepções das pessoas acerca do que as faz feliz e nos seus entendimentos de felicidade, em articulação com os contextos sociais que as produzem, possibilitando o conhecimento, por um lado, das condições sociais que favorecem ou dificultam sentimentos de felicidade e, por outro lado, das práticas que lhe estão associadas e dos significados que lhe são atribuídos. Para tal, propomos uma abordagem extensiva (ao nível dos instrumentos e dimensão da amostra) que permite o acesso aos significados de felicidade na sua relação com as circunstâncias de vida em que estes são produzidos. Esta estratégia possibilitará realçar as complexidades sociais em torno das experiências de felicidade e ajudar a compreender as formas em que esta é inerentemente social.

Assim, centrar-nos-emos em seguida na influência que os contextos sociais têm sobre as percepções de felicidade.

\subsection{Contextos sociais de felicidade}

Ainda que a importância social da felicidade seja transversal - na medida em que cada um de nós valoriza e cultiva a sua própria felicidade e que somos socialmente 
condicionados a aparentar e procurar felicidade - , estudos mostram que os contextos sociais influenciam a percepção de felicidade (Frey \& Stutzer, 2001; Roque Dantas, 2012; 2015; Veenhoven \& Jonkers, 1984). Na verdade, a forma como as pessoas pensam, falam, imaginam e agem acerca de felicidade são influenciadas pelas suas condições sociais (Hampe, 2013).

No mesmo sentido, outros trabalhos concluem que os espaços sociais são diferenciadores das representações sociais de felicidade. Esta diferenciação expressa-se pela relação entre a percepção de sentir felicidade e um conjunto de atributos socialmente diferenciados, em que menores níveis de felicidade assumem maior expressão entre os mais velhos, entre as mulheres e os que detêm menores recursos económicose sócio-culturais. Estes resultados revelam que desigualdades sociais mais vastas trespassam e influenciam as formas de sentir (Roque Dantas, 2015), contribuindo para a compreensão das formas em que a felicidade é inerentemente social.

Mais ainda, a literatura tem vindo a alertar para as consequências nefastas que as desigualdades sociais têm sobre a percepção de felicidade. Mais especificamente, os resultados existentes indicam que a percepção de desigualdade social tem uma forte influência negativa sobre a percepção de felicidade (Alberto Alesina, Tellab \& MacCulloch, 2004; Yang, 2008). Ao mesmo tempo, sabe-se que as pessoas com mais recursos económicos tendem a reportar níveis de felicidade mais elevados (Pickett \& Wilkinson, 2011) e que a percepção de felicidade está relacionada com a posição social ocupada, sendo que posições sociais mais elevadas reportam maiores níveis de felicidade (Kroll, 2011; Veenhoven \& Jonkers, 1984). Neste sentido, importa reter que diferentes estudos, aplicando diferentes metodologias, apontam no mesmo sentido: países com índices mais elevados de desigualdades sociais apresentam níveis mais baixos de bem-estar das suas populações (Di Tella, MacCulloch \& Oswald, 2003; Graham, 2011a; Graham, Chattopadhyay \& Picon, 2010; Pickett \& Wilkinson, 2011; Yang, 2008). Da mesma forma, trabalhos incidindo sobre a realidade portuguesa mostram que a percepção de felicidade está associada a posições mais elevadas na escala social e, pelo contrário, não sentir felicidade surge associado a posições mais baixas na hierarquia social (Brites, 2014; Roque Dantas, 2015).

Vimos já que a idade também parece ser um aspecto relevante para a compreensão da percepção de felicidade, ainda que a sua influência não seja consensual entre diferentes autores.

Num trabalho de referência, Blanchflower e Oswald (2008) concluíram que a relação entre idade e felicidade segue uma tendência que consideraram universal: maior felicidade entre os mais jovens, diminuindo na idade adulta (com o ponto mais baixo entre os 45-51 anos) e aumentando com o avançar da idade. Segundo estes autores, a felicidade, quando representada graficamente ao longo do ciclo de 
vida, desenha a forma de um sorriso: é maior na infância e adolescência, menor na meia idade (à volta dos 45-51 anos) e volta a aumentar na velhice (Blanchflower \& Oswald, 2008). Contrariamente, Veenhoven e Jonkers (1984), e ainda que defendendo uma relação entre a idade e a felicidade, consideram que o envelhecimento influencia negativamente a percepção de felicidade. De acordo com estes autores, há diferenças acentuadas entre países quanto à relação entre felicidade e idade, sendo que estas diferenças decorrem dos contextos sociais em que se processa a avaliação. Neste entendimento, as diferentes circunstâncias em que se desenvolve o processo de avaliação vão ter influência sobre a percepção de felicidade.

Para a realidade portuguesa recente, os resultados contrariam igualmente a tese de universalidade proposta por Blanchflower e Oswald (2008). A felicidade média declarada diminui com o aumento da idade, verificando-se ainda um efeito combinado de idade e sexo que influencia a sua percepção. Na juventude, as mulheres reportam níveis médios mais elevados de felicidade do que os homens, mas nas idades mais avançadas esta tendência inverte-se, verificando-se uma quebra nos níveis médios de felicidade das mulheres e face aos dos homens (Roque Dantas, 2015). Ainda assim, a influência do sexo sobre a percepção de felicidade é menos clara, existindo conclusões diferenciadas quanto à influência de se ser homem ou mulher sobre a percepção de felicidade. A aparente contradição parece dever-se, de acordo com Graham (2011a), a diferenças contextuais que abordagens mais extensivas apenas conseguem captar mas não conseguem explicar.

Importa, pois, perceber qual a relação que a idade, o sexo e a posição social ocupada têm com a ideia de felicidade. Estas variáveis, largamente estudadas na literatura como relevantes para compreender as percepções de felicidade, remetem para diferentes espaços sociais, socializações e ciclos de vida distintos. Quando interrelacionadas, espera-se a cristalização de características sociais e percepções de felicidade, resultantes da evolução sócio-histórica e do contacto com diferentes modelos sociais de felicidade. Assim, e sabendo que a veiculação de modelos sociais em que a felicidade é valorizada é transversal a toda a sociedade, contribuindo para uniformizar formas de procurar, sentir e expressar felicidade (Roque Dantas, 2012), questionamos se os significados sociais atribuídos a felicidade apresentam diferenciação social, nomeadamente em função do sexo, idade e posição social dos indivíduos.

\section{Métodos}

Este artigo trabalha com resultados obtidos por meio de um inquérito sociológico por questionário aplicado na cidade de Lisboa, a residentes na Área Metropolitana de Lisboa, em finais de 2011 e início de 2012². 
Este instrumento permitiu combinar as características de abordagens extensivas (dimensão e sistematicidade da informação) com a recolha de informação intensiva, acedendo, através de perguntas abertas, ao sentido dado à acção de actores sociais envolvidos. Esta abordagem possibilitou conhecer os significados de felicidade pela voz dos indivíduos, explorando os seus entendimentos, bem como as circunstâncias específicas em que se enquadram as percepções dos indivíduos observados.

Lisboa é um espaço urbano com uma população com elevada mobilidade (80,5\% dos passageiros transportados no país e $50 \%$ dos embarcados e $50 \%$ dos desembarcados aéreos), com acesso aos meios de comunicação (72\% tem acesso à internet em casa) e cultura ( $10 \%$ dos museus concentram-se na cidade de Lisboa), além de ter um poder de compra acima da média nacional (INE, 2012) 3. Ora, estas características tornam a população de Lisboa o universo ideal para o estudo da felicidade: população urbana, escolarizada, com capacidade de mobilidade/deslocação e socialmente diferenciada, capacitando a análise para a exploração de regularidades em torno de características que podem traduzir, por um lado, o ciclo de vida (idade), como diferentes socializações e modos de vida (sexo e posição social).

Assim, a estratégia de recolha de informação assentou numa amostra por quotas interrelacionadas (entendendo que cada quota integra um número pré-definido de elementos com determinadas características, mas que estes elementos são seleccionados de forma não aleatória). As quotas definidas são sexo e idade, variáveis que remetem, por um lado, para diferentes socializações e, por outro, para ciclos de vida distintos ${ }^{4}$.

Quanto à sua dimensão, a amostra é constituída por 626 indivíduos, dos quais 332 (53\%) são mulheres e 294 (47\%) são homens; 38,8\% tem idades compreendidas entre os 18 e 34 anos, $35 \%$ entre os 35 e os 54 anos e $26,2 \%$ idades iguais ou superiores a 55 anos $^{5}$.

As variáveis mobilizadas decorrem do questionário aplicado e podem ser consultadas na tabela 1.

Os dados obtidos resultam de um questionário que combina perguntas abertas e fechadas. Se as perguntas fechadas estão orientadas para a quantificação dos seus resultados, as perguntas abertas obrigaram a um tratamento prévio das respostas recorrendo a uma análise do seu conteúdo, antes da sua análise estatística. A codificação das perguntas abertas foi realizada de forma sistemática e objectiva com a finalidade de analisar e comparar as respostas. Esta operação iniciou-se com uma leitura flutuante, procurando semelhanças entre as respostas. As categorias para codificação emergem desta leitura e seguem critérios de 
Tabela 1 Variáveis mobilizadas

\begin{tabular}{l|l}
\hline Variáveis (Respostas) & Descrição das variáveis \\
\hline Sexo (Homem/Mulher) & Sexo do(a) inquirido(a) \\
\hline Idade (<35 anos; 35-55 anos; >55 anos) & Idade do(a) inquirido(a) medida em escalões etários \\
\hline Posição social & $\begin{array}{l}\text { Variável resultante de uma solução unidimensional de uma Análise de } \\
\text { Correspondências Múltiplas (ACM) que remete para uma distribuição } \\
\text { hierarquizada de recursos sociais a partir da disposição das categorias dos } \\
\text { três indicadores - escalão de rendimento, nível de instrução e profissão. A } \\
\text { partir do resultado da ACM foi possível construir um índice de posição social } \\
\text { (variável compósita) que reflecte a complexidade do constructo e que é uma } \\
\text { nova variável quantitativa (estandardizada) que quantifica a posição social. } \\
\text { Esta variável tem média 0 e Desvio Padrão 1. }\end{array}$ \\
\hline
\end{tabular}

\begin{tabular}{|c|c|}
\hline $\begin{array}{l}\text { Comprar tudo o que deseja } \\
\text { (1. Nada importante; } 7 \text {. Muito importante) }\end{array}$ & Aspectos relevantes para a felicidade \\
\hline $\begin{array}{l}\text { Realização profissional } \\
\text { (1. Nada importante; 7. Muito importante) }\end{array}$ & Aspectos relevantes para a felicidade \\
\hline $\begin{array}{l}\text { Ter um emprego estável } \\
\text { (1. Nada importante; } 7 \text {. Muito importante) }\end{array}$ & Aspectos relevantes para a felicidade \\
\hline $\begin{array}{l}\text { Boa progressão na carreira } \\
\text { (1. Nada importante; } 7 \text {. Muito importante) }\end{array}$ & Aspectos relevantes para a felicidade \\
\hline $\begin{array}{l}\text { Autonomia/ controlo sobre a vida } \\
\text { (1. Nada importante; } 7 \text {. Muito importante) }\end{array}$ & Aspectos relevantes para a felicidade \\
\hline $\begin{array}{l}\text { Segurança financeira/poupança } \\
\text { (1. Nada importante; } 7 \text {. Muito importante) }\end{array}$ & Aspectos relevantes para a felicidade \\
\hline $\begin{array}{l}\text { Aproveitar a vida / Fazer o que gosto } \\
\text { (1. Nada importante; } 7 \text {. Muito importante) }\end{array}$ & Aspectos relevantes para a felicidade \\
\hline $\begin{array}{l}\text { Obter a admiração e reconhecimento dos outros } \\
\text { (1. Nada importante; } 7 \text {. Muito importante) }\end{array}$ & Aspectos relevantes para a felicidade \\
\hline $\begin{array}{l}\text { Ter uma relação amorosa } \\
\text { (1. Nada importante; } 7 \text {. Muito importante) }\end{array}$ & Aspectos relevantes para a felicidade \\
\hline $\begin{array}{l}\text { Ter amigos } \\
\text { (1. Nada importante; } 7 \text {. Muito importante) }\end{array}$ & Aspectos relevantes para a felicidade \\
\hline $\begin{array}{l}\text { Seguir os valores/práticas e tradições familiares } \\
\text { (1. Nada importante; } 7 \text {. Muito importante) }\end{array}$ & Aspectos relevantes para a felicidade \\
\hline $\begin{array}{l}\text { Expressar as minhas opiniões e crenças } \\
\text { (1. Nada importante; } 7 \text {. Muito importante) }\end{array}$ & Aspectos relevantes para a felicidade \\
\hline $\begin{array}{l}\text { Dimensão de felicidade } \\
\text { 1: Profissão e segurança económica }\end{array}$ & $\begin{array}{l}\text { Variável estandardizada } \\
\text { (média }=0 \text { e desvio padrão }=1 \text { ) resultante de } \mathrm{ACP} \text { aos indicadores que } \\
\text { medem os aspectos mais relevantes para a felicidade }\end{array}$ \\
\hline $\begin{array}{l}\text { Dimensão de felicidade } \\
\text { 2: Relações interpessoais e valores }\end{array}$ & $\begin{array}{l}\text { Variável estandardizada } \\
\text { (média }=0 \text { e desvio padrão=1) resultante de } \mathrm{ACP} \text { aos indicadores que } \\
\text { medem os aspectos mais relevantes para a felicidade }\end{array}$ \\
\hline $\begin{array}{l}\text { Dimensão de felicidade } \\
\text { 3: Prazer e autonomia }\end{array}$ & $\begin{array}{l}\text { Variável estandardizada } \\
\text { (média }=0 \text { e desvio padrão }=1 \text { ) resultante de } A C P \text { aos indicadores que } \\
\text { medem os aspectos mais relevantes para a felicidade }\end{array}$ \\
\hline $\begin{array}{l}\text { Dimensão de felicidade } \\
\text { 4: Reconhecimento social e consumo }\end{array}$ & $\begin{array}{l}\text { Variável estandardizada } \\
\text { (média }=0 \text { e desvio padrão }=1 \text { ) resultante de } \mathrm{ACP} \text { aos indicadores que } \\
\text { medem os aspectos mais relevantes para a felicidade }\end{array}$ \\
\hline $\begin{array}{l}\text { Ideia de felicidade } \\
\text { (1. Tomar decisões que tenham a vista felicidade; } 2 . \\
\text { Importância do estar bem (consigo mesmo e com os } \\
\text { outros) e da ajuda ao outro; } 3 \text {. Valorização do } \\
\text { bem-estar da família; } 4 \text {. Concretizar objectivos; } 5 \text {. Fazer } \\
\text { o que dá prazer; } 6 \text {. Investir no trabalho; } 7 . \text { Outra) }\end{array}$ & $\begin{array}{l}\text { Variável resultante da questão: } \\
\text { O que é para si o mais importante para ser feliz? }\end{array}$ \\
\hline $\begin{array}{l}\text { Orientação para a acção } \\
\text { (1.Estimular relações interpessoais/ convívio; } \\
\text { 2.Conciliar dimensões da vida; 3.Fazer o que dá } \\
\text { prazer; 4. Desenvolvimento pessoal; } 5 \text {. Estabelecer } \\
\text { objectivos; } 6 \text {. Trabalho; } 7 \text {.Saúde/desporto; } 8 \text {. Outra; } \\
\text { 9. Não faz nada) }\end{array}$ & $\begin{array}{l}\text { Variável resultante da questão: } \\
\text { O que tem feito para ser feliz? }\end{array}$ \\
\hline
\end{tabular}

Fonte: Roque Dantas (2015). 
proximidade (entre as respostas) e exclusividade (cada resposta só pode ser codificada numa única categoria) (Bardin, 1994; Ghiglione \& Matalon, 2001; Guerra, 2006; Roque Dantas, 2016).

A análise aqui desenvolvida envolve a utilização de testes estatísticos. Estes testes, que em seguida passaremos a enunciar, foram mobilizados com o objectivo de aferir a grandeza das relações entre as variáveis.

Assim, para avaliar as relações entre variáveis qualitativas ou categorizadas optou-se pelo teste de independência do qui-quadrado $\left(X^{2}\right)$ e pela análise dos resíduos estandardizados e ajustados $\left(R_{\mathrm{ij}}\right)$ que contribuem para que o resultado seja significativo, permitindo assim avaliar a associação entre categorias da variável ${ }^{6}$.

Por outro lado, quando se procuram as relações entre variáveis de natureza quantitativa e qualitativa, recorremos à análise da variância (one-way e two-way Anova) $(F)$ e ao teste não paramétrico Kruskal-Wallis $(H)^{7}$. As associações entre variáveis quantitativas foram avaliadas através do coeficiente de correlação de Pear$\operatorname{son}(R)$.

Procedeu-se ainda a uma Análise em Componentes Principais (ACP) para sumarizar e descrever a estrutura de relações entre vários indicadores relativos ao mesmo tema ${ }^{8}$.

\section{Resultados}

A análise dos resultados será orientada pelos contributos teóricos previamente apresentados, iniciando-se com a identificação das principais dimensões que contribuem para a felicidade individual. Seguidamente, explora-se a ideação de felicidade através dos entendimentos dos próprios indivíduos e por fim avalia-se as orientações da acção face à felicidade. Em cada um destes pontos será explorada a existência de diferenciação social, nomeadamente as regularidades e diferenças relativas ao sexo, à idade e à posição social.

\subsection{Dimensões de felicidade}

Tendo presente a influência conjunta de diferentes dimensões sobre as percepções de felicidade, tal como ficou expresso na revisão da literatura apresentada, foram reunidos e apresentados aos inquiridos diversos aspectos que as pessoas tendem a identificar como relevantes para a sua felicidade, pedindo-lhes que classificassem a sua importância. Assumindo que estes têm uma importância diferenciada para cada pessoa, procurou-se identificar a estrutura de relações inerentes aos seguintes indicadores: 1. Comprar tudo o que deseja; 2. Realização profissional; 3. Ter um 
Tabela 2 Dimensões de felicidade (Análise em Componentes Principais com rotação Varimax)

\begin{tabular}{lcc}
\hline & $\begin{array}{c}\text { Contribuição em cada } \\
\text { componente }\end{array}$ & $\begin{array}{c}\text { Variância explicada } \\
\text { (\%) }\end{array}$ \\
\hline Componente 1 - Profissão e segurança económica & 0,814 & \\
Boa progressão na carreira & 0,780 & 23,3 \\
Ter emprego estável & 0,697 & \\
Realização profissional & 0,628 & 12,3 \\
Segurança financeira/poupança & & \\
Componente 2 - Relações interpessoais e valores & 0,683 & \\
Seguir os valores e tradições familiares & 0,623 & 10,8 \\
Espressar as minhas opiniões e crenças & 0,570 & \\
Ter uma relação amorosa & 0,450 & \\
Ter amigos & & \\
Componente 3 - Prazer e autonomia & 0,709 & \\
Aproveitar a vida/fazer o que gosto & 0,721 & \\
Autonomia/controlo sobre a vida & & \\
Componente 4 - Reconhecimento social e consumo & 0,803 & \\
Comprar o que deseja & & \\
Obter admiração e reconhecimento dos outros & & \\
\hline
\end{tabular}

Fonte: Roque Dantas (2015).

emprego estável; 4. Boa progressão na carreira; 5. Autonomia/controlo sobre a vida; 6. Segurança financeira/poupança; 7. Aproveitar a vida/fazer o que gosto; 8. Obter a admiração e reconhecimento dos outros; 9. Ter uma relação amorosa; 10. Ter amigos; 11. Seguir os valores/práticas e tradições familiares; 12. Expressar as minhas opiniões e crenças. Através de uma análise em Componentes Principais foi possível extrair quatro componentes que resumem os indicadores propostos e que explicam 55,5\% da variância total (tabela 2$)^{9}$.

Com base nestes resultados podemos identificar quatro dimensões relacionadas com a felicidade: uma dimensão relacionada a profissão e segurança económica; uma dimensão focada nas relações interpessoais e valores orientadores; uma terceira dimensão que reúne aspectos de prazer individual e autonomia; e, por último, uma dimensão que agrega indicadores de reconhecimento social e consumo (tabela 2).

Uma primeira análise acerca da valorização destas quatro dimensões de felicidade entre homens e mulheres não identifica diferenças estatisticamente significativas. Contudo, e apesar dos testes estatísticos não aferirem uma relação entre as variáveis, podemos perceber algumas dissemelhanças quanto à forma como homens e por mulheres valorizam as dimensões propostas. Mais especificamente, a leitura das médias permite perceber que as mulheres valorizam positivamente as dimensões profissão e segurança económica, relações interpessoais e valores e prazer e 
Tabela 3 Valorização média das dimensões de felicidade entre sexo, grupo etário e posição social

\begin{tabular}{|c|c|c|c|c|}
\hline & $\begin{array}{c}\text { Profissão } \\
\text { e segurança } \\
\text { económica }\end{array}$ & $\begin{array}{c}\text { Relações } \\
\text { interpessoais } \\
\text { e valores }\end{array}$ & $\begin{array}{c}\text { Prazer } \\
\text { e autonomia }\end{array}$ & $\begin{array}{l}\text { Reconhecimento } \\
\text { social e consumo }\end{array}$ \\
\hline Sexo & ns & ns & ns & ns \\
\hline Homem & $-0,058$ & $-0,035$ & $-0,038$ & 0,077 \\
\hline Mulher & 0,053 & 0,029 & 0,029 & $-0,070$ \\
\hline Grupo etário & ns & $\begin{array}{c}F_{(2,592)}=6,170 \\
p=0,002\end{array}$ & $\begin{array}{c}F_{(2,592)}=21,513 \\
p<0,001\end{array}$ & ns \\
\hline $18-34$ & 0,048 & $-0,153$ & 0,256 & $-0,025$ \\
\hline $35-54$ & $-0,049$ & 0,015 & 0,003 & 0,057 \\
\hline$>=55$ & $-0,003$ & 0,209 & $-0,406$ & $-0,042$ \\
\hline Posição social média & ns & ns & $R=0,111 ; p=0,007$ & ns \\
\hline
\end{tabular}

Nota: Os valores apresentados referem-se aos resultados dos seguintes testes estatísticos: Anova (F) e Coeficiente de Correlação de Pearson (R), bem como aos valores médios que cada uma das dimensões assume entre as categorias consideradas. Estas variáveis são estandardizadas, perdendo-se a escala original, mas não a orientação. A leitura dos valores deve ter em conta os valores superiores à média (valores positivos), que estão realçados a negrito e os que são inferiores à média (valores negativos).

Fonte: Roque Dantas (2015).

autonomia; ao contrário, os homens valorizam mais, em média, o reconhecimento social e consumo (tabela 3).

Da mesma forma, não foram encontradas associações (estatisticamente significativas) entre a posição social ocupada e a valorização de cada uma destas dimensões. A excepção é a correlação positiva e significativa (ainda que baixa) entre a valorização da autonomia/prazer e a posição social ocupada. Esta correlação, indica que a valorização desta dimensão aumenta a par do aumento da posição social, ou seja, que pessoas com uma posição social mais elevada tendem a valorizar mais a importância da autonomia e do prazer para a sua felicidade (tabela 3).

Os resultados indicam que a importância destas dimensões é semelhante em todos os respondentes e que todas elas contribuem para a sustentação de ideias comuns de felicidade. Ou seja, todas as quatro dimensões - profissão e segurança económica; relações interpessoais e valores orientadores; prazer individual e capacidade de escolha; reconhecimento social e consumo - concorrem para influenciar a percepção de felicidade dos indivíduos e todas fazem parte da sua realidade, dificultando a sua diferenciação. Mais ainda, o facto destas dimensões serem relevantes independentemente do sexo e do estatuto social, poderá ser revelador de condicionamentos sociais - sentir o que é esperado - , contribuindo para a uniformização das expressões de felicidade e das formas de a sentir.

No entanto, a análise efectuada em função da idade revela algumas diferenças. Mais especificamente, verifica-se que a dimensão das relações interpessoais, 


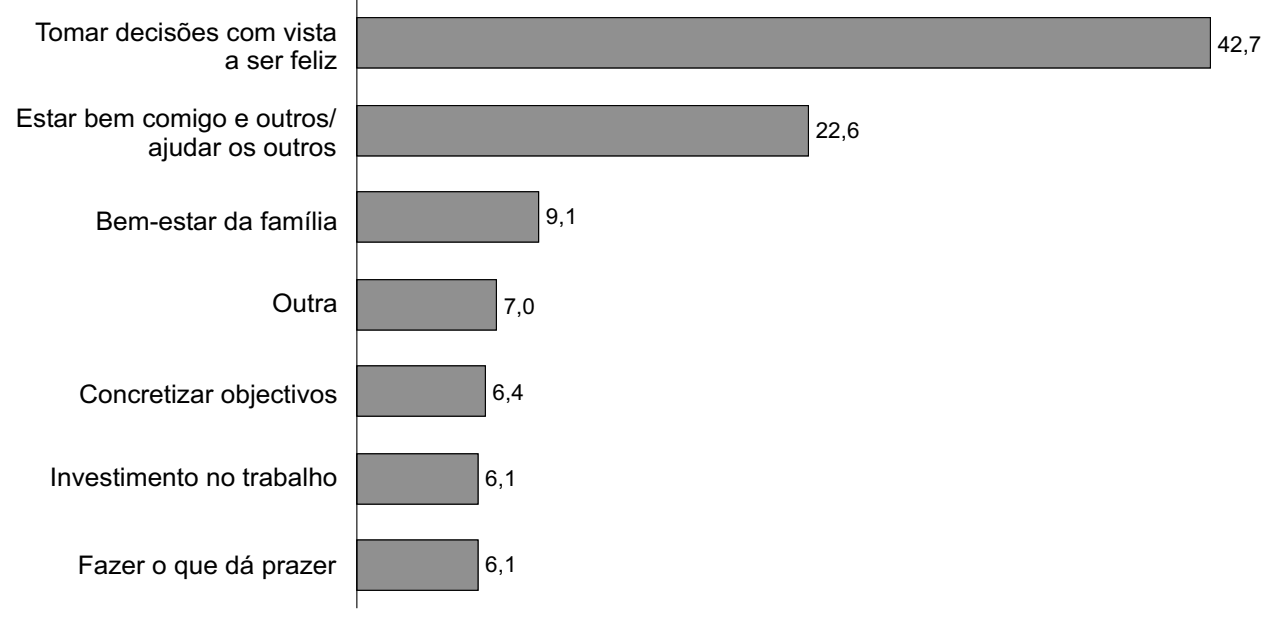

Figura 1 O que é mais importante para ser feliz? (\%)

Fonte: Roque Dantas (2015).

tradições e valores é diferentemente valorizada em função do grupo etário. Os mais jovens tendem a desvalorizar esta dimensão, intensificando-se a sua importância com o aumento da idade. Por sua vez, a valorização média desta dimensão é superior no grupo etário com 55 ou mais anos, sendo estas diferenças estatisticamente significativas (tabela 3).

Pelo contrário, quando testámos a relação entre os escalões etários e a dimensão prazer/autonomia, verificámos que a valorização deste aspecto diminui com o aumento da idade, ou seja, são os jovens quem (em média) valoriza mais o prazere a autonomia e os mais velhos quem valoriza menos, sendo que há diferenças significativas entre todos os grupos (tabela 3).

Quanto às outras dimensões identificadas - consumo/reconhecimento social e segurança profissional e financeira - não se detectam diferenças estatísticas significativas entre os três grupos etários.

Os resultados revelam que, apesar dos aspectos que influenciam a felicidade estarem amplamente identificados e de, globalmente, a sua importância ser consensual, há diferenças que decorrem do percurso individual. Importa, pois, aprofundar o conhecimento acerca da forma como as pessoas experienciam e expressam os seus desejos de felicidade, questão sobre a qual nos debruçaremos em seguida. 


\subsection{Ideia de felicidade}

Ainda que grande parte dos estudos assuma que a felicidade é algo que todos desejamos e procuramos (Joshanloo, Lepshokova, Panyusheva, Natalia, Poon, Yeung, Sundaram, Achoui, Asano, Igarashi, Tsukamoto, Rizwan, Khilji, Ferreira, Pang, Ho, Han, Bae \& Jiang, 2013; Joshanloo \& Weijers, 2014), os resultados do ponto anterior sugerem a importância de conhecer os significados associados à felicidade de forma aprofundada. Pretende-se agora contribuir para o conhecimento do que as pessoas expressam como importante para a sua felicidade: como a idealizam e como a esperam concretizar. Mais ainda, pretende-se explorar se a ideia de felicidade é socialmente transversal, ou pelo contrário, é possível encontrar diferenciação social na produção dos seus significados.

De acordo com os nossos resultados, a ideia de felicidade assenta na responsabilidade individual. De facto, quando questionados sobre o que é mais importante para ser feliz, a maior parte dos/as inquiridos/as indica a importância de tomar decisões que tenham em vista a felicidade (42,7\%), assumindo a sua felicidade como uma responsabilidade pessoal e dependente das decisões por si tomadas (ver figura 1). Este resultado vem claramente reforçar as considerações de McMahon (2009; 2010), nomeadamente que a concepção actual de felicidade, herdada do Iluminismo, propaga a crença de que todos podemos, devemos e seremos felizes. Assim pensada, a felicidade é um direito humano ao alcance de todos e só depende da acção individual.

As respostas indicam ainda a importância do estar bem (consigo mesmo e com os outros) e da ajuda ao outro (22,6\%), a valorização do bem-estar da família $(9,1 \%)$, concretizar objectivos $(6,4 \%)$, fazer o que dá prazer $(6,1 \%)$ e investir no trabalho $(6,1 \%)$.

Contudo, as estratégias para alcançar felicidade não são semelhantes em toda a amostra, verificando-se especificidades decorrentes do sexo, da posição social e da idade dos/as respondentes. Nomeadamente, encontramos diferenças estatísticas significativas entre homens e mulheres relativamente à expressão de ideias de felicidade. Esta relação decorre da maior probabilidade de as mulheres identificarem estar bem comigo e outros/ajudar os outros como uma forma de ser feliz. A grandeza desta relação fica expressa tanto ao nível do peso das respostas $(64,9 \%$ dos/as que indicam esta ideia de felicidade são mulheres), como da relação estatística entre as categorias. Refira-se ainda que os resultados parecem contrariar estereótipos de género que tendem a associar às mulheres a centralidade do bem-estar da família, que nesta amostra colhe maior percentagem de respostas entre os homens (56,7\% dos que indicam o bem-estar da família como relevante para a concretização da sua felicidade são homens), ainda que a relação não seja estatisticamente significativa 
Tabela 4 O que é mais importante para ser feliz? Por sexo, grupo etário e posição social

\begin{tabular}{|c|c|c|c|c|c|c|}
\hline & $\begin{array}{c}\text { Tomar } \\
\text { decisões }\end{array}$ & $\begin{array}{c}\text { Estar } \\
\text { bem/ajudar }\end{array}$ & $\begin{array}{l}\text { Bem-estar } \\
\text { família }\end{array}$ & $\begin{array}{l}\text { Concretizar } \\
\text { objectivos }\end{array}$ & $\begin{array}{l}\text { Fazer o que } \\
\text { dá prazer }\end{array}$ & $\begin{array}{l}\text { Investimento } \\
\text { no trabalho }\end{array}$ \\
\hline \multicolumn{7}{|l|}{$\begin{array}{l}\text { Sexo } \\
n s\end{array}$} \\
\hline Homem & 73 & 26 & 17 & 9 & 7 & 9 \\
\hline $\begin{array}{l}\% \text { linha } \\
\text { Res.Aj. }\end{array}$ & $\begin{array}{c}52,1 \% \\
1,4\end{array}$ & $\begin{array}{c}35,1 \% \\
-2,4^{*}\end{array}$ & $\begin{array}{c}56,7 \% \\
1,0\end{array}$ & $\begin{array}{c}65,2 \% \\
1,8\end{array}$ & $\begin{array}{c}35,0 \% \\
-1,2\end{array}$ & $\begin{array}{c}45,0 \% \\
-0,2\end{array}$ \\
\hline Mulher & 67 & 48 & 13 & 8 & 13 & 11 \\
\hline $\begin{array}{l}\% \text { linha } \\
\text { Res.Aj. }\end{array}$ & $\begin{array}{c}47,9 \% \\
-1,4 \\
\end{array}$ & $\begin{array}{c}64,9 \% \\
2,4^{*}\end{array}$ & $\begin{array}{c}43,3 \% \\
-1,0 \\
\end{array}$ & $\begin{array}{c}34,8 \% \\
-1,8 \\
\end{array}$ & $\begin{array}{c}65,0 \% \\
1,2 \\
\end{array}$ & $\begin{array}{c}55,0 \% \\
0,2 \\
\end{array}$ \\
\hline \multicolumn{7}{|l|}{$\begin{array}{l}\text { Grupo etário } \\
\chi_{(12)}^{2}=33,050 ; \rho=0,001\end{array}$} \\
\hline $18-34$ & 61 & 22 & 6 & 12 & 14 & 11 \\
\hline $\begin{array}{l}\% \text { linha } \\
\text { Res.Aj. }\end{array}$ & $\begin{array}{c}43,6 \% \\
1,1\end{array}$ & $\begin{array}{c}29,7 \% \\
-2,1^{*}\end{array}$ & $\begin{array}{c}20,0 \% \\
-2,4^{*}\end{array}$ & $\begin{array}{c}57,1 \% \\
1,6\end{array}$ & $\begin{array}{c}70,0 \% \\
2,8^{*}\end{array}$ & $\begin{array}{c}55,0 \% \\
1,4\end{array}$ \\
\hline $\begin{array}{l}35-54 \\
\% \text { linha } \\
\text { Res. Aj. }\end{array}$ & $\begin{array}{c}46 \\
32,9 \% \\
-0,8\end{array}$ & $\begin{array}{c}28 \\
37,8 \% \\
0,5\end{array}$ & $\begin{array}{c}17 \\
56,7 \% \\
2,6^{*}\end{array}$ & $\begin{array}{c}6 \\
28,6 \% \\
-0,7\end{array}$ & $\begin{array}{c}3 \\
15,0 \% \\
-2,0^{*}\end{array}$ & $\begin{array}{c}9 \\
45,0 \% \\
0,9\end{array}$ \\
\hline $\begin{array}{l}>=55 \\
\% \text { linha } \\
\text { Res.Aj. }\end{array}$ & $\begin{array}{c}33 \\
23,6 \% \\
-0,3 \\
\end{array}$ & $\begin{array}{c}24 \\
32,4 \% \\
1,8 \\
\end{array}$ & $\begin{array}{c}7 \\
23,3 \% \\
-0,1\end{array}$ & $\begin{array}{c}3 \\
14,3 \% \\
-1,1 \\
\end{array}$ & $\begin{array}{c}3 \\
15,0 \% \\
-1,0 \\
\end{array}$ & $\begin{array}{c}0 \\
0,0 \% \\
-2,6^{*} \\
\end{array}$ \\
\hline $\begin{array}{l}\text { Posição social média } \\
\text { H }(6)=14,248 ;=\rho 0,027\end{array}$ & 0,06 & 0,16 & 0,15 & 0,00 & 0,23 & 0,50 \\
\hline
\end{tabular}

Nota: Os valores apresentados referem-se aos resultados dos seguintes testes estatísticos: teste t à igualdade de médias $(\mathrm{t})$, teste de independência do qui-quadrado $(\chi 2)$, teste Kruskall-Wallis $(\mathrm{U})$, bem como aos valores médios que cada uma das dimensões assume entre as categorias consideradas, valores absolutos, \% em linha e resíduos estandardizados e ajustados entre categorias.

Legenda: Res.Aj.: resíduos estandardizados e ajustados entre categorias. * indica significância estatística (|Z| > 1,96; nível de confiança de $95 \%)$. Os valores realçados a negrito indicam uma associação positiva entre as categorias.

A leitura dos valores da variável posição social deve ter em conta que, por se tratar de uma variável estandardizada, os valores superiores à média (positivos), que estão realçados a negrito e os que são inferiores à média (negativos).

A categoria outra foi retirada da tabela porque reunia respostas muitos díspares, impossibilitando a sua análise como um todo.

Fonte: Roque Dantas (2015).

(tabela 4). No mesmo sentido, os nossos resultados indicam que a concretização de objectivos é uma estratégia para alcançar felicidade mais comum entre as mulheres, ainda que a diferença entre mulheres e homens não seja significativa.

Do mesmo modo, a ideia de felicidade não é semelhante em todas as idades. Mais especificamente, entre os mais novos destaca-se fazer o que me apetece/dá prazer e entre os do grupo etário intermédio o bem-estar da família. A leitura da tabela 4 permite ainda perceber que tomar decisões e fazer o que dá prazer perdem relevância quantitativa com o aumentar da idade. 
Igualmente, foram identificadas diferenças decorrentes da posição social ocupada. Os grupos sociais com posição social média mais elevada tendem a valorizar o investimento no trabalho como estratégia para alcançar felicidade, mas também o bem-estar da família e fazer o que dá prazer. Pelo contrário, posições sociais médias mais baixas destacam a concretização de objectivos, tomar decisões e estar bem consigo e outros.

Assim, apesar da ideação de felicidade ser semelhante e consensual, é possível encontrar diferenças sociais subjacentes, revelando que algumas pessoas terão maior capacidade de definir e viver a sua felicidade do que outras. Se socialmente somos condicionados para desejar e idealizar felicidade, dentro de determinados parâmetros que nos chegam pela música, pelos filmes, pelos livros, pelos processos de socialização, mas também pelas redes sociais e comunicação social, a interiorização e exteriorização destes modelos não é semelhante a todo o tecido social, tal como revelam os resultados.

\subsection{Orientação da acção face a felicidade}

No ponto anterior foi possível perceber que a concepção de felicidade está associada à responsabilidade individual, ou seja, à convicção de que a felicidade depende das decisões pessoais. Ora, se o ideal de felicidade partilhado fica marcado pela crença nas capacidades e responsabilidade individual, também as orientações para a acção - no sentido de se ser feliz - estão imbuídas deste modelo. A expressão life is what you make of it (Hampe, 2013), ou o destino está nas nossas mãos, ilustra bem a convicção de que a felicidade é o resultado da acção individual, ou seja, das decisões tomadas e da forma como se planeia e organiza a vida.

Neste sentido, iremos agora explorar a orientação das acções desenvolvidas com vista à felicidade, bem como a sua diferenciação social em função do sexo, idade e posição social.

Entre as acções desenvolvidas para se ser feliz, destaca-se a dedicação ao trabalho/estudo (25\%) e o investimento nas relações interpessoais e convívio (24,8\%). Em seguida, e com menor peso percentual, surgem respostas no sentido de gozar a vida $(12,4 \%)$, estabelecer objectivos (12,2\%) e dedicação ao auto-conhecimento/desenvolvimento pessoal (10,8\%). Refira-se igualmente que $4 \%$ dos/as inquiridos/as refere não ter feito nada com vista a ser feliz.

Também a orientação da acção apresenta diferenças de sexo, de idade e de posição social. No que diz respeito ao sexo, apesar de globalmente se observar uma relação significativa com a orientação da acção, não se verificam associações específicas (reveladas pela análise dos resíduos estandardizados e ajustados) entre categorias das variáveis (tabela 5). Quantitativamente, a leitura da tabela permite 
Tabela 5 Orientação da acção por sexo, grupo etário e posição social

\begin{tabular}{|c|c|c|c|c|c|c|c|c|}
\hline & $\begin{array}{l}\text { Estimular } \\
\text { relações } \\
\text { interpessoais } \\
\text { / convívio }\end{array}$ & $\begin{array}{l}\text { Conciliar } \\
\text { dimensões } \\
\text { da vida }\end{array}$ & $\begin{array}{l}\text { Fazer o } \\
\text { que dá } \\
\text { prazer }\end{array}$ & $\begin{array}{l}\text { Des. } \\
\text { pessoal }\end{array}$ & $\begin{array}{l}\text { Estabelecer } \\
\text { objectivos }\end{array}$ & Trabalho & $\begin{array}{l}\text { Saúde/ } \\
\text { desporto }\end{array}$ & $\begin{array}{c}\text { Não faz } \\
\text { nada }\end{array}$ \\
\hline \multicolumn{9}{|l|}{$\begin{array}{l}\text { Sexo } \\
\chi_{(7)}^{2}=20,152 ; \rho=0,005\end{array}$} \\
\hline Homem & 63 & 11 & 38 & 25 & 28 & 71 & 15 & 11 \\
\hline $\begin{array}{l}\text { \% linha } \\
\text { Res.Aj. }\end{array}$ & $\begin{array}{c}23,7 \% \\
-1,0\end{array}$ & $\begin{array}{c}4,1 \% \\
1,0\end{array}$ & $\begin{array}{c}14,3 \% \\
1,3\end{array}$ & $\begin{array}{c}9,4 \% \\
-1,0\end{array}$ & $\begin{array}{c}10,5 \% \\
-1,0\end{array}$ & $\begin{array}{c}26,7 \% \\
1,0\end{array}$ & $\begin{array}{l}5,6 \% \\
-0,3\end{array}$ & $\begin{array}{c}4,1 \% \\
0,0\end{array}$ \\
\hline Mulher & 79 & 7 & 33 & 37 & 42 & 72 & 19 & 12 \\
\hline $\begin{array}{l}\% \text { linha } \\
\text { Res.Aj. }\end{array}$ & $\begin{array}{c}25,7 \% \\
1,0\end{array}$ & $\begin{array}{c}2,3 \% \\
-1,0\end{array}$ & $\begin{array}{c}10,7 \% \\
-1,3\end{array}$ & $\begin{array}{c}12,1 \% \\
1,0\end{array}$ & $\begin{array}{c}13,7 \% \\
1,0\end{array}$ & $\begin{array}{c}23,5 \% \\
-1,0\end{array}$ & $\begin{array}{c}6,2 \% \\
0,3\end{array}$ & $\begin{array}{c}3,9 \% \\
0,0\end{array}$ \\
\hline \multicolumn{9}{|l|}{$\begin{array}{l}\text { Grupo etário } \\
\chi_{(16)}^{2}=34,282 ; \rho=0,005\end{array}$} \\
\hline $18-34$ & 61 & 4 & 32 & 16 & 31 & 60 & 7 & 7 \\
\hline $\begin{array}{l}\% \text { linha } \\
\text { Res.Aj. }\end{array}$ & $\begin{array}{c}43,0 \% \\
1,2\end{array}$ & $\begin{array}{l}22,2 \% \\
-1,5\end{array}$ & $\begin{array}{c}45,1 \% \\
1,2\end{array}$ & $\begin{array}{l}25,8 \% \\
-2,2^{*}\end{array}$ & $\begin{array}{c}44,3 \% \\
1,0\end{array}$ & $\begin{array}{c}42,0 \% \\
0,9\end{array}$ & $\begin{array}{c}20,6 \% \\
-2,2^{*}\end{array}$ & $\begin{array}{c}30,4 \% \\
-0,8\end{array}$ \\
\hline $\begin{array}{l}35-54 \\
\% \text { linha } \\
\text { Res. Aj. }\end{array}$ & $\begin{array}{c}43 \\
30,3 \% \\
-1,5\end{array}$ & $\begin{array}{c}5 \\
27,8 \% \\
-0,7\end{array}$ & $\begin{array}{c}23 \\
32,4 \% \\
-0,6\end{array}$ & $\begin{array}{c}30 \\
48,4 \% \\
2,2^{*}\end{array}$ & $\begin{array}{c}21 \\
30,0 \% \\
-1,0\end{array}$ & $\begin{array}{c}59 \\
41,3 \% \\
1,6\end{array}$ & $\begin{array}{c}16 \\
47,1 \% \\
1,4\end{array}$ & $\begin{array}{c}6 \\
26,1 \% \\
-1,0\end{array}$ \\
\hline $\begin{array}{l}>=55 \\
\% \text { linha } \\
\text { Res.Aj. }\end{array}$ & $\begin{array}{c}38 \\
26,8 \% \\
0,3\end{array}$ & $\begin{array}{c}9 \\
50,0 \% \\
2,4^{*}\end{array}$ & $\begin{array}{c}16 \\
22,5 \% \\
-0,6\end{array}$ & $\begin{array}{c}16 \\
25,8 \% \\
0,0\end{array}$ & $\begin{array}{c}18 \\
25,7 \% \\
0,0\end{array}$ & $\begin{array}{c}24 \\
16,8 \% \\
-2,8^{*}\end{array}$ & $\begin{array}{c}11 \\
32,4 \% \\
0,9\end{array}$ & $\begin{array}{c}10 \\
43,5 \% \\
2,0^{*}\end{array}$ \\
\hline $\begin{array}{l}\text { Posição social média } \\
F_{(8,564)}=2,749 ; \rho=0,006\end{array}$ & 0,08 & $-0,09$ & $-0,06$ & 0,30 & 0,05 & 0,00 & 0,07 & $-0,61$ \\
\hline
\end{tabular}

Nota: Os valores apresentados referem-se aos resultados dos seguintes testes estatísticos: análise de variância $(F)$ e teste de independência do qui-quadrado $(\chi 2)$, bem como aos valores médios que cada uma das dimensões assume entre as categorias consideradas, valores absolutos, \% em linha e resíduos estandardizados e ajustados entre categorias

Legenda: Res.Aj.: resíduos estandardizados e ajustados entre categorias. * indica significância estatística ( $|Z|>1,96$; nível de confiança de $95 \%)$. Os valores realçados a negrito indicam uma associação positiva entre as categorias.

A leitura dos valores da variável posição social deve ter em conta que, por se tratar de uma variável estandardizada, os valores superiores à média (valores positivos), que estão realçados a negrito e os que são inferiores à média (valores negativos).

Fonte: Roque Dantas (2015).

perceber que, entre as mulheres se valoriza as relações interpessoais/convívio, o trabalho, o estabelecer objectivos, e o auto-conhecimento/desenvolvimento pessoal. Os homens apontam com mais frequência a importância do trabalho, estimular as relações interpessoais/convívio e fazer o que dá prazer como estratégia para ser feliz.

Da mesma forma, recorremos ao teste de independência do qui-quadrado para avaliar a relação entre a orientação da acção e o grupo etário dos/as inquiridos/as. Os resultados revelam uma associação estatisticamente significativa entre as duas variáveis. Mais especificamente, pela análise dos resíduos estandardizados e ajustados, 
percebemos que a relação fica marcada pela maior probabilidade de entre os mais velhos (com 55 ou mais anos) a acção estar orientada para a conciliação entre diferentes dimensões da vida ${ }^{10}$ e para não fazer nada. O grupo etário entre os 35 e os 54 anos tende a orientar a sua acção no sentido do auto-conhecimento/desenvolvimento pessoal, dimensão que outros estudos revelam estar associada a posturas de vida mais conscientes e autónomas, bem como orientadas para a concretização e envolvimento na acção (Csikszentmihalyi, 2009; Lane, 2000; Roque Dantas, 2012).

Igualmente, através de uma análise de variância (Anova), foi possível perceber que a orientação da aç̧ão fica marcada pela posição social ocupada. Se entre as posições sociais mais baixas, as respostas vão no sentido de não fazer nada, conciliar diferentes dimensões e fazer o que se gosta, entre os grupos sociais mais favorecidos destaca-se o auto-conhecimento, a saúde/desporto, as relações interpessoais, os objectivos e a dedicação ao trabalho (tabela 5). Relembramos os contributos de Welzel, Inglehart e Kligemann (2003) que consideram que o desenvolvimento sócio-económico diminui os constrangimentos à capacidade de escolha e de decisão e aumenta os recursos individuais. No mesmo sentido, o aumento dos recursos sócio-económicos alarga o espectro das actividades possíveis, das aspirações de realização pessoal, de autonomia, aumento da capacidade individual de escolha e controlo sobre a vida.

Os resultados permitem concluir que as orientações da acção face à felicidade são socialmente diferenciadas e incorporam desigualdades sociais mais vastas. Sentir, pensar, imaginar e procurar felicidade não são opções meramente individuais, destacadas da organização social. Ainda que associadas pelos inquiridos às capacidades individuais e qualidade das suas decisões, estão profundamente marcadas pelas circunstâncias, pelos percursos e pelo meio social de inserção. Este resultado é indicador de que a forma como os significados são socialmente produzidos e incorporados se reflecte na interpretação de nós próprios e na construção do sentido das nossas aç̧ões.

\section{Considerações finais}

A análise realizada permitiu perceber que há diferenças sociais - decorrentes da posição social, da idade e do sexo - quanto às estratégias para alcançar felicidade e quanto às idealizações de felicidade. Estas diferenças indicam que há desigualdades sociais que trespassam as percepções de felicidade e que contribuem para distinguir as formas de sentir, experienciar e expressar felicidade. Sendo a felicidade influenciada por desigualdades sociais mais vastas, está então intimamente ligada às condições de vida e às diferenças socialmente produzidas pelas oportunidades 
disponíveis. Ainda assim, no entendimento das pessoas observadas, a felicidade é apontada como uma responsabilidade individual, expressa pela ideia de que ser feliz é uma opção pessoal (Roque Dantas, 2008) e depende principalmente da capacidade de tomar decisões que tenham em vista a felicidade. Paralelamente, a literatura aponta para a importância das condições sociais para a percepção de felicidade.

Se as condições sociais influenciam a percepção de felicidade, os discursos não traduzem a sua importância; pelo contrário, diluem-na na responsabilização individual e na culpabilização dos que fracassam. O modelo dominante é de que, mesmo perante condições adversas e que nos são alheias e impossíveis de controlar, sermos felizes só depende da vontade própria.

Este modelo tem ainda inerente a conviç̧ão de que as pessoas são autónomas e têm o poder de moldar as suas vidas, sendo a felicidade o resultado desse trabalho. Mas as condições sociais limitam a liberdade, a capacidade de escolha e acção, sendo que a forma como as pessoas pensam, falam, agem e imaginam são fortemente influenciadas pelas suas circunstâncias.

Se a ideia de felicidade ao alcance de todos serviu princípios de igualdade e desejos de construir uma sociedade melhor, tal como ficou expresso na declaração de independência dos Estados Unidos da América, este princípio orientador foi-se transformando e foi criando a ilusão da possibilidade de acesso à felicidade, encobrindo desigualdades sociais das formas de sentir, tornando-se a felicidade uma promessa por cumprir.

Estas conclusões são necessariamente parciais, mas constituem um primeiro contributo para a compreensão aprofundada dos significados sociais de felicidade, situando os entendimentos dos actores sociais nos contextos em que são produzidos. Futuras investigações deverão ter em conta que as manifestações de felicidade reflectem contextos sócio-culturais e que quaisquer variações da sua expressão devem ser interpretadas face às transformações sociais ocorridas. Impõe-se, por isso, constituir indicadores de felicidade que completem a medição da sua expressão, nomeadamente com a avaliação dos seus significados e das práticas que lhe estão associadas. Este estudo, articulado ainda com indicadores contextuais, permitirá ir mais longe na compreensão das formas de sentir felicidade nas suas características inerentemente sociais.

\section{Agradecimentos}

Este estudo foi financiado pela Fundação para a Ciência e a Tecnologia (SFRH / BD / 60889 / 2009 e PTDC/IVC-ESCT/0073/2014) e pelo Centro Interdisciplinar de Ciências Sociais (CICS.NOVA), apoiado pela FCT/MCTES através de Fundos Nacionais (UID/SOC/04647/2013). 


\section{Notas}

1. Em 2008, na página da World Database of Happiness (Veenhoven, n.d.), era possível contabilizar 5671 artigos científicos dedicados ao tema da felicidade; em 2013, no mesmo site, ascendiam a 7246 e, em 2018, são já 10348. Igualmente, em 2016 uma pesquisa na EBSCO com o termo happiness, devolvia cerca de 8355 registos de resultados em revistas académicas e em 2018 são cerca de 31488. No mesmo sentido, Kahneman e Kruger (2006) referem que, só na área da Economia, entre 2001 e 2005, foram publicados mais de 100 artigos utilizando medidas de felicidade ou de satisfação com a vida.

2. O inquérito sociológico por questionário foi desenvolvido no âmbito de uma investigação para doutoramento. Disponível para consulta em toda a sua extensão em: https://run.unl.pt/handle/10362/15119.

3. A região de Lisboa concentra algumas particularidades consideradas essenciais para a abordagem aqui seguida. A cidade de Lisboa é a capital do país e o maior núcleo urbano: a população da Grande Lisboa representa cerca de $20 \%$ da do país (PORDATA, 2011); concentra cerca de 37,2\% do PIB per capita nacional, 29,3\% das empresas, 35,4\% do pessoal ao serviço e 33,6\% das exportações nacionais (INE, 2012). Esta região destaca-se igualmente pelos elevados níveis de escolaridade, assegurando $30 \%$ dos diplomados de Portugal e $31 \%$ dos alunos de ensino superior do espaço nacional (PORDATA, 2011).

4. A recolha dos dados foi feita nas entradas e nas estações de metro da cidade de Lisboa, entre Outubro de 2011 e Fevereiro de 2012, permitindo o acesso a uma população socialmente diferenciada. A decisão de procurar pessoas em diferentes espaços físicos da cidade e não circunscrever a análise a um espaço geográfico específico assenta na decisão de aceder a pessoas de diferentes estratos sociais, com diferentes percursos profissionais e com inserções sociais distintas, criando condições para que as respostas contenham variabilidade que permita o conhecimento aprofundado do fenómeno.

5. Dado a semelhante estrutura da amostra definida pelo European Social Survey, série 5 para a região de Lisboa (632 respostas, com uma repartição por sexos semelhante $-60 \%$ das respostas são de mulheres e 39,9\% são de homens - , assim como, por grupos etários maior peso das respostas dos mais velhos (42,6\%), 33\% de respostas do grupo central e $24,4 \%$ dos mais novos), é representativa da estrutura demográfica da região de Lisboa.

6. Os resultados do teste de independência do qui-quadrado só foram analisados quando estavam cumpridos os seus pressupostos de aplicabilidade, nomeadamente: 1 . Não mais de $20 \%$ das células com frequência esperada inferior a 5; 2 . Nenhuma célula com frequência esperada inferior a 1 (Laureano, 2013; Marôco, 2011; Sheskin, 2004).

7. O cálculo e análise de resultados relativos a estes testes cumprem os seus pressupostos de aplicação, optando-se por testes não paramétricos nas situações de não cumprimento e conforme sugestões de manuais de estatística de referência (Guimarães \& Cabral, 1997; Laureano, 2013; Marôco, 2011).

8. A análise em componentes principais cumpre os requisitos e procedimentos de aplicação recomendados na bibliografia de referência (Laureano, 2013; Marôco, 2011; Reis, 2001). 
9. Os requisitos de aplicação foram verificados através da estatística Kaiser-Meyer-Olkin $(\mathrm{KMO}=0,7)$ e teste de esfericidade de Bartlett $\left(\chi^{2}(6)=1064,030, \mathrm{p}<0,001\right)$. As componentes foram extraídas com base no critério de Kaiser e gravados os scores factoriais resultantes.

10. Refira-se que o grupo etário dos 55 ou mais anos é maioritariamente $(63,4 \%)$ constituído por pessoas com idades entre os 55 e os 65 anos, ou seja, em idade activa.

Por decisão pessoal, a autora do presente texto não escreve segundo o novo acordo ortográfico.

\section{Referências}

Alberto Alesina, R. Di T., \& MacCulloch, R. (2004). Inequality and happiness: Are Europeans and Americans different?, Journal of Public Economics, 88(9-10), 2009-2042.

Argyle, M. (2013a). The psychology of happiness. Londres e Nova Iorque: Taylor \& Francis. Argyle, M. (2013b). The social psychology of everyday life. Londres e Nova Iorque: Taylor \& Francis.

Bardin, L. (1994). Análise de conteúdo. Lisboa: Edições 70.

Baudelot, C., \& Gollac, M. (2003). Travailler pour être heureux? Le bonheur et le travail en France. Paris: Fayard.

Blanchflower, D. G., \& Oswald, A. J. (2008). Is well-being u-shaped over the life cycle?, Social Science E Medicine, 66(8), 1733-1749.

Brites, R. (2014). Os impactos da crise no bem-estar subjectivo. VIII Congresso Português de Sociologia - 40 Anos de Democracia(s), Progressos, Contradições e Prospectivas. Évora.

Csikszentmihalyi, M. (1997). Finding flow. The psychology of engagement with everyday life. Nova Iorque: Basic Books.

Csikszentmihalyi, M. (2009). Flow. Nova Iorque: HarperCollins.

Di Tella, R., MacCulloch, R. J., \& Oswald, A. J. (2003). The macroeconomics of happiness. The Review of Economics and Statistics, 85(4), 809-827.

Easterlin, R. A. (2001). Income and happiness: Towards a unified theory. The Economic Journal, 111(473), 465-484.

Frey, B. S. (2009). Felicidade. Uma revolução na economia. Lisboa: Gradiva.

Frey, B. S., \& Stutzer, A. (2000). Happiness, economy and institutions. The Economic Journal, 110(466), 918-938.

Frey, B. S., \& Stutzer, A. (2001). Happiness and economics: How the economy and institutions affect human well-being. Princeton e Oxford: Princeton University Press.

Ghiglione, R., \& Matalon, B. (2001). O inquérito: Teoria e prática. Oeiras: Celta Editora.

Graham, C. (2011a). O que nos faz felizes por esse mundo fora. O paradoxo dos camponeses felizes e dos milionários miseravelmente infelizes. Alfragide: Texto Editores.

Graham, C. (2011b). The pursuit of happiness?: An economy of well-being. Washington, D.C.: Brookings Institution Press. 
Graham, C., Chattopadhyay, S., \& Picon, M. (2010). Adapting to adversity: Happiness and the 2009 economic crisis in the United States. Social Research, 77(2), 715-748.

Guerra, I. C. (2006). Pesquisa qualitativa e análise de conteúdo: Sentidos e formas de uso. Lisboa: Principia.

Guimarães, R., \& Cabral, J. S. (1997). Estatística. Lisboa: McGraw Hill.

Hampe, M. (2013). Happiness as Ideology and Experience. The Problem of Unity and Plurality. ETH Zurich, Department of Humanities, Social and Political Sciences, Chair for Philosophy.

Helliwell, J. F. (2003). How's life? Combining individual and national variables to explain subjective well-being. Economic Modelling, 20(2), 331-360.

Hills, P., \& Argyle, M. (1998). Positive moods derived from leisure and their relationship to happiness and personality. Personality and Individual Differences, 25(3), 523-535.

Hyman, L. (2014). Happiness: Understandings, narratives and discourses. Palgrave Macmillan.

INE. (2012). Anuário da Região de Lisboa. Lisboa: Instituto Nacional de Estatística.

Inglehart, R., Foa, R., Peterson, C., \& Welzel, C. (2008). Development, freedom, and rising happiness: A global perspective (1981-2007). Perspectives on Psychological Science, 3(4), 264-285.

Joshanloo, M., Lepshokova, Z. K., Panyusheva, T., Natalia, A., Poon, W.-C., Yeung, V. W.-I., Sundaram, S., Achoui, M., Asano, R., Igarashi, T., Tsukamoto, S., Rizwan, M., Khilji, I. A., Ferreira, M. C., Pang, J. S., Ho, L. S., Han, G., Bae, J., \& Jiang, D.-Y. (2013). Cross-cultural validation of fear of happiness scale across 14 national groups. Journal of Cross-Cultural Psychology, 45(2), 246-264.

Joshanloo, M., \& Weijers, D. (2014). Aversion to Happiness Across Cultures: A Review of Where and Why People are Averse to Happiness. Journal of Happiness Studies, 15(3), 717-735.

Kahneman, D., \& Krueger, A. B. (2006). Developments in the measurement of subjective well-being. Journal of Economic Perspectives, 20(1), 3-24.

Kroll, C. (2011). Towards a sociology of happiness: Examining social capital and subjective well-being across subgroups of society. Sociologia. London School of Economics and Political Science (LSE), Londres.

Lane, R. E. (2000). The loss of happiness in market democracies. New Haven e Londres: Yale University Press.

Laureano, R. (2013). Testes de hipóteses com o spss - o meu manual de consulta rápida. Lisboa: Silabo.

Layard, R. (2005). Happiness: Lessons from a new science. Londres: Penguin Books Limited. Marôco, J. (2011). Análise estatística com o SPSS statistics. Pêro Pinheiro: ReportNumber.

McMahon, D. M. (2009). Uma história da felicidade (1. ${ }^{a}$ ed.). Lisboa: Edições 70.

McMahon, D.M. (2010). What does the ideal of happiness mean? Social Research, 77(2), 469.

Oishi, S., Graham, J., Kesebir, S., \& Galinha, I. C. (2013). Concepts of happiness across time and cultures. Personality and Social Psychology Bulletin, 39(5), 559-577.

Pickett, K., \& Wilkinson, R. (2011). The spirit level: Why greater equality makes societies stronger. Londres: Bloomsbury Press. 
PORDATA. (2011). Retrato de Lisboa, indicadores 2011. Lisboa: Fundação Francisco Manuel dos Santos.

Reis, E. (2001). Estatística multivariada aplicada. Sílabo.

Roque Dantas, A. (2008). ue vida viver? Para uma análise sociológica da felicidade enquanto projecto de vida. Sociologia. FCSH/UNL, Lisboa.

Roque Dantas, A. (2012). A construção social da felicidade. Lisboa: Colibri.

Roque Dantas, A. (2015). A felicidade enquanto recurso emocional socialmente desigual: Para uma abordagem sociológica do sentir. Sociologia. FCSH/UNL, Lisboa.

Roque Dantas, A. (2016). Análise de Conteúdo: Um caso de aplicação ao estudo dos valores e representações sociais. In M. Lisboa (Ed.), Metodologias de investigação sociológica (pp. 261-286). V. N. Famalicão: Edições Húmus.

Sheskin, D. J. (2004). Handbook of parametric and nonparametric statistical procedures (3rd ed.). Cleveland: Chapman \& Hall/CRC.

Veenhoven, R. (n.d.). World database of happiness. The Netherlands: Erasmus University Rotterdam. Retrieved from http:/ / worlddatabaseofhappiness.eur.nl

Veenhoven, R., \& Jonkers, T. (1984). Conditions of happiness (D.Reidel P, Vol. 2). Berlin: Springer.

Yang, Y. (2008). Social inequalities in happiness in the United States, 1972 to 2004: An age-period-cohort analysis. American Sociological Review, 73(2), 204-226.

Welzel, C., Inglehart, R., \& Kligemann, H.-D. (2003). The theory of human development: A cross-cultural analysis. European Journal of Political Research, 42(3), 341-379.

Data de submissão: 09/11/2018 | Data de aceitação: 17/12/2018 